\title{
Induction of sclerotia in Sclerotium rolfsii by short low-temperature treatment
}

\author{
CARroll D. RaWN \\ Biology Department, Seton Hall University, South Orange, New Jersey 07079, USA
}

(Received 7 August 1990; revised 15 January 1991; accepted 28 January 1991)

\begin{abstract}
When grown on two agar media in Petri dishes a Sclerotium rolfsii Sacc. isolate produced sclerotia in different patterns, predominantly at the colony centre on one medium (glucose/yeast extract) but at the dish wall on the other (glucose/ammonium nitrate). However, on both media a short cold treatment $\left(3 \mathrm{~h}\right.$ at $5{ }^{\circ} \mathrm{C}$ ) of colonies grown at $24^{\circ} \mathrm{C}$ temporarily interrupted growth and induced subsequent sclerotial formation in a ring where the colony margin was at the time of the cold shock. A second cold treatment $1 \mathrm{~d}$ after the first induced a sclerotial ring but negated the effect of the first treatment. The results support the view that interruption of hyphal growth triggers sclerotial formation.
\end{abstract}

\section{Introduction}

Effects of many nutritional, chemical and physical factors on formation of sclerotia by Sclerotium rolfsii Sacc. in culture have been reviewed (Aycock, 1966; Chet \& Henis, 1975; Willetts, 1978; Punja, 1985). A recurrent argument is that generally sclerotia do not form in culture until mycelial growth has been restricted in some way. Despite the importance of this view in stimulating research, some of which has led to some contrary results (Chet \& Henis, 1975), there seems to be nothing in the $S$. rolfsii literature about the use of abrupt, brief lowtemperature treatment as a tool to study the connection of growth restriction to sclerotial formation. Studies have typically used continuous low temperature treatments for several days rather than for a brief period (Higgins, 1927; Townsend, 1957; Abeygunawardena \& Wood, 1957; Wheeler \& Waller, 1965; Zoberi, 1980). In Hypomyces solani f. sp. cucurbitae a brief cold treatment stimulated the formation of primordia of perithecia (Wilson, 1968), which developmentally are similar to some sclerotia (Willetts, 1972). If interference with apical dominance of hyphae at the growing edge of a colony triggers sclerotial formation (Willetts, 1978), then a short restriction of growth by low temperature might affect sclerotial formation. The purpose of this study was to determine whether brief, low-temperature treatments that reversibly inhibit growth affect production of sclerotia in an $S$. rolfsii isolate.

Abbreviations: GYE, glucose/yeast extract agar medium; GAN, glucose/ammonium nitrate agar medium.

\section{Methods}

Growth conditions. The isolate of $S$. rolfsii (from Carolina Biological Supply Co., Burlington, NC, USA) was grown in plastic Petri dishes, $90 \times 15 \mathrm{~mm}$. Glucose/yeast extract agar medium (GYE) contained $10 \mathrm{~g}$ glucose, $2 \mathrm{~g}$ yeast extract and $15 \mathrm{~g}$ agar per litre of distilled water. GYE was used without (pH 5.8) and after ( $\mathrm{pH} \mathrm{6.8)} \mathrm{adjustment} \mathrm{of}$ $\mathrm{pH}$. Glucose/ammonium nitrate agar medium (GAN), modified from Joham (1943), contained $10 \mathrm{~g}$ glucose, $1.0 \mathrm{~g} \mathrm{NH}_{4} \mathrm{NO}_{3}, 0.2 \mathrm{~g}$ $\mathrm{MgSO}_{4} .7 \mathrm{H}_{2} \mathrm{O}, 0.7 \mathrm{~g} \mathrm{~K}_{2} \mathrm{HPO}_{4}, 0.15 \mathrm{~g} \mathrm{KCl}, 0.001 \mathrm{~g}$ thiamin. $\mathrm{HCl}$, $0.002 \mathrm{~g} \mathrm{FeSO}_{4}, 0.002 \mathrm{~g} \mathrm{MnCl}_{2}, 0.002 \mathrm{~g} \mathrm{ZnSO}_{4}$ and $15 \mathrm{~g}$ agar per litre of distilled water. The $\mathrm{pH}$ was adjusted to $6 \cdot 8$, except when the effect of $\mathrm{pH}$ was tested (pH 4.5-8.0). Media were sterilized for $17 \mathrm{~min}$ at $121^{\circ} \mathrm{C}$ in $500 \mathrm{ml}$ lots, cooled to $45^{\circ} \mathrm{C}$, and poured into dishes, $25 \mathrm{ml}$ each. The dish diameter at the surface of the medium was $86 \mathrm{~mm}$.

Inoculum plugs were cut with a cork borer $(5 \mathrm{~mm}$ diam.) from the edge of 3-d-old colonies and put in the centre of test dishes, fungal surface down. Cultures were sealed with tape and kept in darkness in a $24^{\circ} \mathrm{C}$ incubator, except during $5{ }^{\circ} \mathrm{C}$ treatments. Results here represent at least three trials of a type, four cultures per treatment. Mean ( \pm SD) numbers of sclerotia were determined for four cultures per treatment.

Low temperature treatment. Cultures were put in a $5{ }^{\circ} \mathrm{C}$ room once or twice, at the times specified in Results, and returned to $24^{\circ} \mathrm{C}$. To estimate how fast the temperature in culture dishes fell after transfer from incubator to cold room, a thermometer was put horizontally through the wall of a sealed dish to lie flat on top of the medium, bulb at the dish centre. Three dishes were monitored on $3 \mathrm{~d}$. Radii of replicate colonies, measured from inoculum plug to colony edge, differed by $10 \%$ or less. Media components were obtained from Difco (Bacto-agar), Gibco (yeast extract), Sigma (thiamin. $\mathrm{HCl}$ ) and Fisher Scientific (all others, ACS grade).

\section{Results}

Colonies on GAN grew to the dish wall, radius $40 \mathrm{~mm}$, in $4 \mathrm{~d}$ (Fig. $1 a$ ) and then produced 350 to 500 sclerotial 

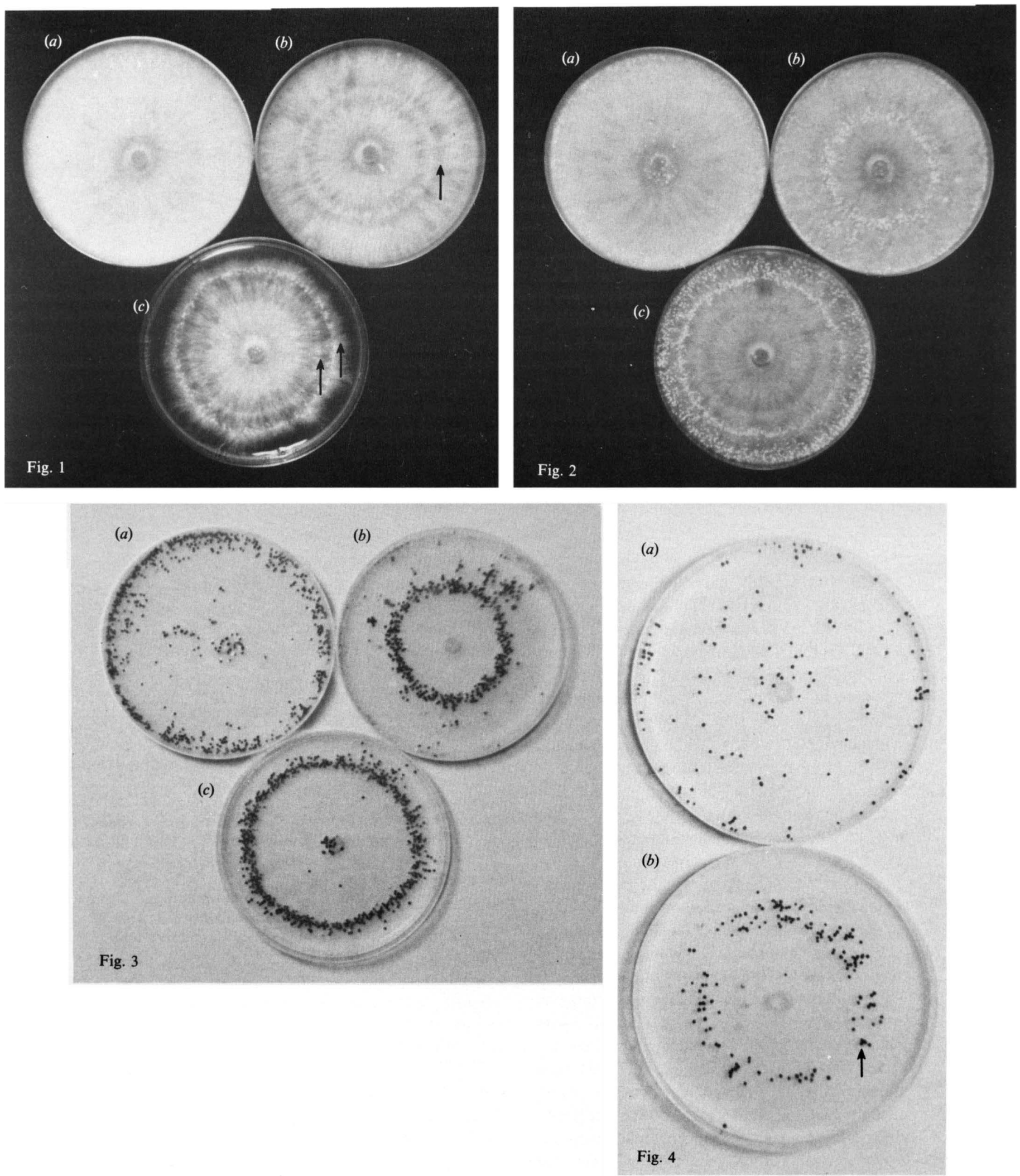

Figs 1-4. S. rolfsii colonies (in 9-cm-diam. dishes) after growth on GAN for $4 \mathrm{~d}$ (Fig. 1), $5 \mathrm{~d}$ (Fig. 2) or $9 \mathrm{~d}$ (Figs 3 and 4). Inoculum disks are at the centre. Incubation was at $24^{\circ} \mathrm{C}$ except during cold $\left(3 \mathrm{~h}\right.$ at $\left.5{ }^{\circ} \mathrm{C}\right)$ treatments. Arrows mark the colony edge at treatment times in Figs 1 and 4. In Figs $1-3(1 \%$ glucose) colonies were untreated $(a)$, treated once after $2 \mathrm{~d}(b)$, or treated after both $2 \mathrm{~d}$ and $3 \mathrm{~d}(c)$. Sclerotia are absent in Fig. $1(a, b)$, present as white initials in Fig. $1(c)$ and $2(a-c)$, and are mature in Fig. 3. Fig. $4(0.3 \%$ glucose), mature sclerotia on untreated colonies $(a)$ and colonies treated for $3 \mathrm{~h}$ at $5{ }^{\circ} \mathrm{C}$ after $2 \mathrm{~d}(b)$; compare with Fig. $3(a, b)$. 
initials near the wall (Fig. 2a); these matured to dark brown by $9 \mathrm{~d}$ (Fig. $3 a$ ). Growth of 2-d-old colonies, radius $20-24 \mathrm{~mm}$, was temporarily arrested by a $3-4 \mathrm{~h}$ exposure to $5{ }^{\circ} \mathrm{C}$. After returning to $24^{\circ} \mathrm{C}$, growth resumed in $2-3 \mathrm{~h}$, a mycelial band formed behind the position of the edge of the colony at treatment time, and the colony radius was $30-34 \mathrm{~mm}$ after $24 \mathrm{~h}, 10-20 \%$ less than the control. The band thickened by $4.5 \mathrm{~d}$ as the colony grew to the wall (Fig. 1b). In the band and the sparser area behind it were hyphal strands (Townsend \& Willetts, 1954). At about $5 \mathrm{~d}$ a ring of initials appeared in and behind the mycelial band (Fig. $2 b$ ) and later more appeared beyond the ring. Most that matured were in the ring (Fig. $3 b$ ).

In colonies chilled at $2 \mathrm{~d}$ and again at $3 \mathrm{~d}$ a second mycelial band that formed behind the colony edge was hidden by a ring of white initials (Fig. 1c), which appeared $10-12 \mathrm{~h}$ after treatment, before the colony reached the wall. Tiny initials (not visible in Fig. 1c) formed in and behind the first band; these did not mature (Figs $2 c$ and $3 c$ ). Twice-chilled colonies reached the wall in $5-5.5 \mathrm{~d}$ and formed more initials beyond the ring (Fig. $2 c$ ), but most outside the ring did not mature (Fig. $3 c$ ). The cold treatments did not significantly affect the total number of mature sclerotia, $426 \pm 33$ per dish in a representative test. Initials that failed to mature were not counted.

Lowering the glucose concentration in GAN to $0.3 \%$ reduced mycelial mass visibly. It decreased the number of sclerotia by two-thirds and changed their distribution (compare Figs $3 a$ and $4 a$ ). A $3 \mathrm{~h}$ cold treatment still produced a sclerotial ring (Fig. $4 b$ ), associated with a faint mycelial band, but the number of mature sclerotia was not significantly affected (143 \pm 21 per dish).

Unlike control colonies on GAN (Fig. $3 a$ ), those on GYE formed sclerotia predominantly in a compact central mass with few at the dish wall. However, treatment at $5{ }^{\circ} \mathrm{C}$ for $3-4 \mathrm{~h}$ gave results similar to those described above for GAN.

Changing the $\mathrm{pH}$ of GYE to 6.8 and that of GAN to $4 \cdot 5,5,6$ or 8 did not alter the responses to one and two cold treatments, but radial growth rate on GAN was $15 \%$ less $(\mathrm{pH} 8)$ or $15 \%$ more $(\mathrm{pH} 4.5$ and 5) than at $\mathrm{pH} 6.8$. Given this small difference, treatments were done slightly later ( $\mathrm{pH} 8)$ or earlier ( $\mathrm{pH} 4.5$ and 5).

Shortening the cold periods to $1 \mathrm{~h}$ gave sclerotial rings and mycelial bands on GAN at pH 6.8 and GYE at pH 5.8 as described above. A $30 \mathrm{~min}$ exposure did the same in most tests. The $30 \mathrm{~min}$ and some $60 \mathrm{~min}$ treatments induced obviously fainter mycelial bands and fewer sclerotia in the rings than longer treatments and more at the dish wall (on GAN) or the colony centre (on GYE), i.e. where controls typically formed them. Treatments of less than $30 \mathrm{~min}$ had no effect.
After a $2{ }^{\circ} \mathrm{C}$ rise when moving cultures to the cold room, the temperature in sealed dishes fell to about $19^{\circ} \mathrm{C}$ at $10 \mathrm{~min}, 13^{\circ} \mathrm{C}$ at $20 \mathrm{~min}, 8^{\circ} \mathrm{C}$ at $40 \mathrm{~min}$ and $5^{\circ} \mathrm{C}$ at $60 \mathrm{~min}$. An exposed thermometer registered $5^{\circ} \mathrm{C}$ within $5 \mathrm{~min}$.

\section{Discussion}

The chill-induced formation of sclerotia associated with the mycelial bands agrees with the known connection of hyphal strands and localized branching to sclerotial formation in $S$. rolfsii (Townsend \& Willetts, 1954; Willetts, 1972; Henis et al., 1973). The results presented here support the view that restriction of mycelial growth leads to sclerotial formation (Henis $e t$ al., 1965; Wheeler \& Waller, 1965; Willetts, 1978). Unlike the previous temperature studies, cited in the Introduction, the effective treatments here were very short and caused changes in sclerotial formation associated with only temporary and brief growth restriction.

The reason that sclerotial patterns differ on different media, as shown here and by others (Wheeler \& Sharan, 1965; Henis et al., 1973; Shapira et al., 1984; Aycock, 1966), is not known. However, the similarity of treatment results on the media used here shows that the results were not artefacts of one medium alone and did not occur only when a colony was otherwise predisposed to a particular sclerotial pattern.

The appearance within 10-12 h of a ring of sclerotia on twice-chilled GAN colonies was as rapid as that after other abrupt treatments such as cutting (Henis et al., 1965; Hadar et al., 1981). The absence of a second ring of mature sclerotia on twice-chilled colonies suggests that the same treatment applied twice can both start and stop events that lead to sclerotia in agreement with the arguments of Willetts $(1972,1978)$. A cold period might start sclerotial formation by slowing hyphal growth and removing apical dominance at the colony edge and, when repeated, interfere with development of those initials as it started the process anew at the colony edge some distance away.

Although initials did not appear as fast on once-chilled colonies as on twice-chilled ones, it appeared that a single treatment at $2 \mathrm{~d}$ set a priority associated with the rapidly formed mycelial band, since the first initials that appeared (the ones that usually matured) did so in a ring at that band. Perhaps a 2-d-old colony was incapable of a full response, as suggested by other results (Hadar et al., 1981), or perhaps one treatment predisposed mycelium to respond more rapidly to a second one. Okon et al. (1972) stressed the investigational value of chemical treatments that induce sclerotia on cue; brief tempera- 
ture manipulations that do so without the need to change the medium may also be useful in studies of several aspects of sclerotial production by $S$. rolfsii.

This work was supported by a grant from the Seton Hall University Research Council.

\section{References}

Abeygunawardena, D. V. W. \& Wood, R. K. S. (1957). Factors affecting the germination of sclerotia and mycelial growth of Sclerotium rolfsii Sacc. Transactions of the British Mycological Society 40, 221-231.

AYCOCK, R. (1966). Stem rot and other diseases caused by Sclerotium rolfsii. North Carolina Agricultural Experiment Station. Technical Bulletin no. 174.

Chet, I. \& Henis, Y. (1975). Sclerotial morphogenesis in fungi. Annual Review of Phytopathology 13, 169-192.

Hadar, Y., Henis, Y. \& Chet, I. (1981). The potential for the formation of sclerotia in submerged mycelium of Sclerotium rolfsii. Journal of General Microbiology 122, 137-141.

Henis, Y., Chet, I. \& Avizohar-Hershenzon, Z. (1965). Nutritional and mechanical factors involved in mycelial growth and production of sclerotia by Sclerotium rolfsii in artificial medium and amended soil. Phytopathology 55, 87-91.

HENIS, Y., OKON, Y. \& CHET, I. (1973). The relationship between early hyphal branching and formation of sclerotia in Sclerotium rolfsii. Journal of General Microbiology 79, 147-150.

HigGins, B. B. (1927). Physiology and parasitism of Sclerotium rolfsii Sacc. Phytopathology 17, 417-448.
JoHAM, H. E. (1943). A nutritional study of the fungus Sclerotium rolfsii. $\mathrm{MSc}$ thesis, A. and M. College of Texas, USA

OKON, Y., CHET, I. \& HeNIS, Y. (1972). Lactose-induced synchronous sclerotium formation in Sclerotium rolfsii and its inhibition by ethanol. Journal of General Microbiology 71, 465-470.

PunJA, Z. K. (1985). The biology, ecology, and control of Sclerotium rolfsii. Annual Review of Phytopathology 23, 97-127.

Shapira, R., Henis, Y., Sklan, D. \& Chet, I. (1984). Changes in fatty acids during morphogenesis in Sclerotium rolfsii. Journal of General Microbiology 130, 1183-1191.

TownSEND, B. B. (1957). Nutritional factors influencing the production of sclerotia by certain fungi. Annals of Botany 21, 153-166.

Townsend, B. B. \& WilletTs, H. J. (1954). The development of sclerotia of certain fungi. Transactions of the British Mycological Society 37, 213-221.

WheEler, B. E. J. \& ShaRAN, N. (1965). The production of sclerotia by Sclerotium rolfsii. I. Effects of varying the supply of nutrients in an agar medium. Transactions of the British Mycological Society 48, 291301 .

WHEELER, B. E. J. \& WALLER, J. M. (1965). The production of sclerotia by Sclerotium rolfsii. II. The relationship between mycelial growth and initiation of sclerotia. Transactions of the British Mycological Society 48, 303-314.

WILLETTS, H. J. (1972). The morphogenesis and possible evolutionary origins of fungal sclerotia. Biological Reviews 47, 515-536.

WILlETTS, H. J. (1978). Sclerotium formation. In The Filamentous Fungi, vol. 3, pp. 197-213. Edited by J. E. Smith \& D. R. Berry. New York: John Wiley.

WILSON, D. M. (1968). Physiology of sexual reproduction in Hypomyces solani f. sp. cucurbitae. V. Influence of tyrosinase on perithecial primordium formation. Phytopathology 58, 1697-1699.

ZOBERI, M. H. (1980). Some nutritional factors regulating formation of sclerotia of Sclerotium rolfsii. Canadian Journal of Botany 58, 24842490. 